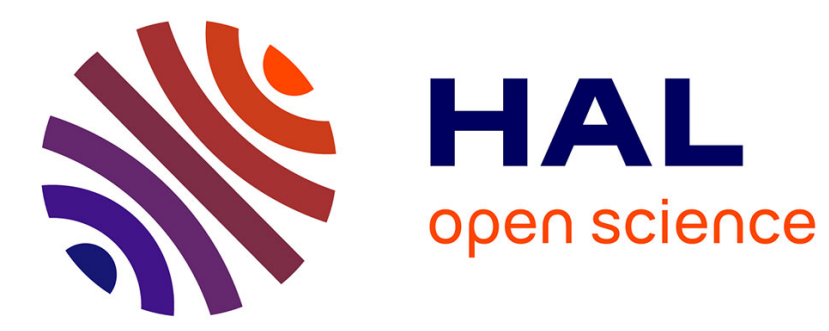

\title{
Synthesis of Aromatic Sulfones from SO2 and Organosilanes, Under Metal-free Conditions
}

Niklas von Wolff, Joëlle Char, Xavier Frogneux, Thibault Cantat

\section{To cite this version:}

Niklas von Wolff, Joëlle Char, Xavier Frogneux, Thibault Cantat. Synthesis of Aromatic Sulfones from SO2 and Organosilanes, Under Metal-free Conditions. Angewandte Chemie International Edition, 2017, 56, pp.5616-5619. 10.1002/anie.201702311 . cea-01510322

\section{HAL Id: cea-01510322 https://hal-cea.archives-ouvertes.fr/cea-01510322}

Submitted on 19 Apr 2017

HAL is a multi-disciplinary open access archive for the deposit and dissemination of scientific research documents, whether they are published or not. The documents may come from teaching and research institutions in France or abroad, or from public or private research centers.
L'archive ouverte pluridisciplinaire HAL, est destinée au dépôt et à la diffusion de documents scientifiques de niveau recherche, publiés ou non, émanant des établissements d'enseignement et de recherche français ou étrangers, des laboratoires publics ou privés.

\section{(c)(1)}

Distributed under a Creative Commons Attribution| 4.0 International License 


\title{
Synthesis of Aromatic Sulfones from $\mathrm{SO}_{2}$ and Organosilanes, Under Metal-free Conditions
}

\author{
Niklas von Wolff," Joëlle Char, \# Xavier Frogneux and Thibault Cantat*[a] \\ [a] NIMBE, CEA, CNRS, Université Paris-Saclay, CEA Saclay 91191 Gif-sur-Yvette \\ cedex, France \\ E-mail: thibault.cantat@cea.fr
}

[\#] Both authors contributed equally to this work.

\begin{abstract}
The conversion of $\mathrm{SO}_{2}$ to arylsulfones has been achieved for the first time under metal-free conditions, by reacting $\mathrm{SO}_{2}$ with (hetero)arylsilanes and alkylhalides, in the presence of a fluoride source. The mechanism of this transformation has been elucidated based on DFT calculations, which highlight the influence of $\mathrm{SO}_{2}$ in promoting C-Si bond cleavage.
\end{abstract}

The sulfone functional group ( $\left.\mathrm{RSO}_{2} \mathrm{R}^{\prime}\right)$ has found widespread applications in organic chemistry, due to its unique physico-chemical properties (stability, lipophilicity, Hbonding etc.),[1] and many arylsulfone derivatives are currently exploited as drugs (e.g. bicalutamide, eletriptan and Vioxx ${ }^{[2]}$ or herbicides. In recent years, heteroarylsulfones were also shown to exhibit important biological activity.[3] Whereas classical synthesis of sulfones rely on the oxidation of sulfides or the sulfonylation of arenes under harsh conditions, [4] the introduction of sulfones in pharmaceuticals has called for the development of mild and step efficient methodologies. An alternative route utilizes $\mathrm{SO}_{2}$ as a sulfonyl cation/anion synthon via the formation of an intermediate sulfinate anion that undergoes $S$-alkylation to yield sulfones (Scheme 1). This strategy has been successfully applied by Willis and coworkers, who were able to generate sulfinate anions from $\mathrm{SO}_{2}$ surrogates (DABCO $\left(\mathrm{SO}_{2}\right)_{2}$ (DABSO), $\mathrm{K}_{2} \mathrm{~S}_{2} \mathrm{O}_{5}$, etc.) with arylmagnesium and aryllithium species. ${ }^{[5]}$ Using stoichiometric or catalytic quantities of metal compounds, the method has then been extended to milder nucleophiles, such as organo-zinc and organo-boron reagents, to improve the tolerance to functional groups. ${ }^{[6]}$ For example, arylsulfinates could be obtained from boronic acids, using palladium and gold catalysts. ${ }^{[7]}$ Because arylboronic acids are compatible with alkylhalides, Shavnya et al. demonstrated for the first time, in 2015, the preparation of sulfones in a single step from $\mathrm{SO}_{2}$ surrogates.[6b] Interestingly, air and moisture stable organosilanes could also be used for the synthesis of sulfones using a copper(I) oxide as catalyst with $\mathrm{SO}_{2}$ surrogates and alkylhalides. ${ }^{[8]}$ In order to circumvent the use of toxic organometallic reagents or metal catalysts, the preparation of sulfones under metal-free conditions is still to be accomplished. In this perspective, we report herein the one-step fluoride mediated synthesis of aryl and heteroarylsulfones from aryl and heteroarylsilanes under metal-free conditions. 


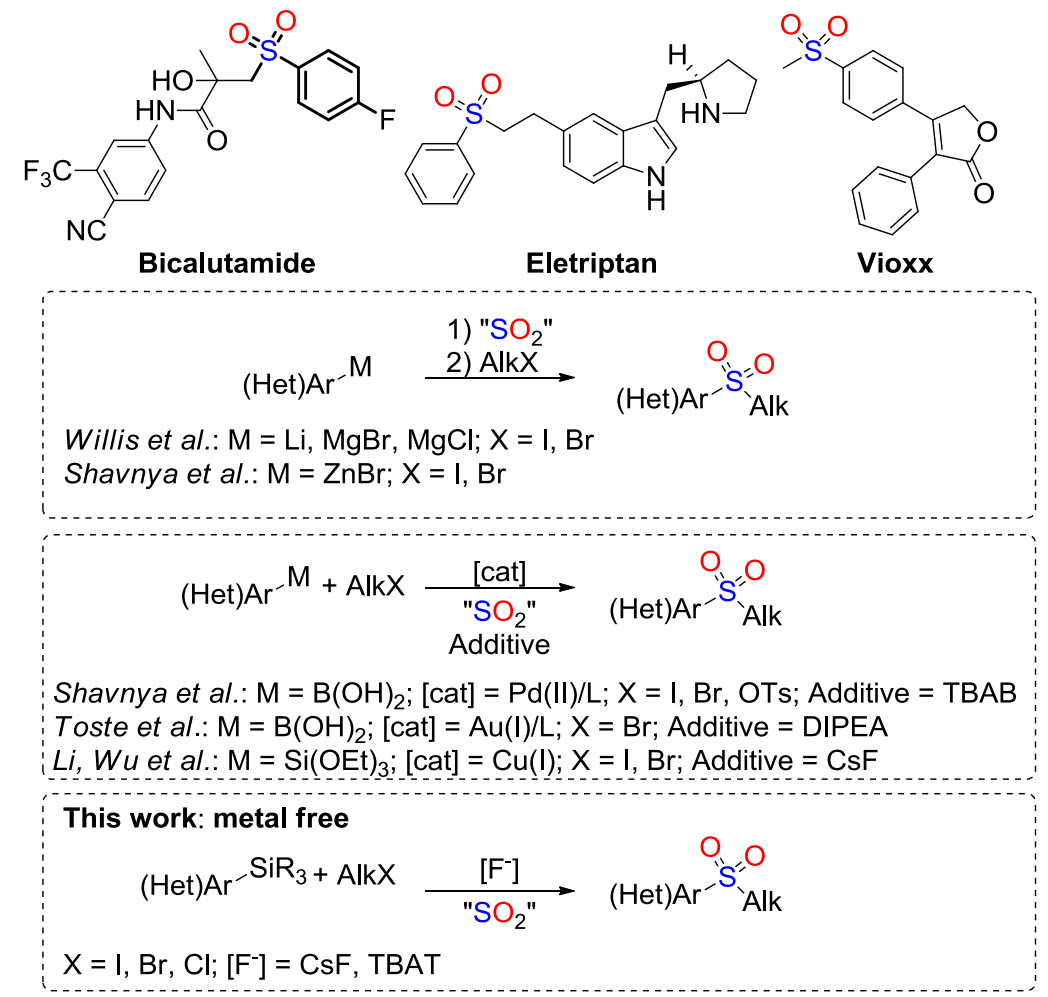

Scheme 1. Some representative sulfone-containing drugs and trends in state of the art sulfone synthesis from $\mathrm{SO}_{2}$.

Organosilanes are very mild nucleophiles and a fluoride source or a base is needed to activate the low polar $\mathrm{C}-\mathrm{Si}$ bond and facilitate transmetallation to a metal catalyst.[9] Interestingly, we have recently reported on the fluoride-mediated carboxylation of heteroarylsilanes with $\mathrm{CO}_{2}$, where $\mathrm{CO}_{2}$ acts both as a reagent and as a catalyst.[10] Reasoning that $\mathrm{SO}_{2}$ is a stronger Lewis acid than $\mathrm{CO}_{2}$, we have sought to promote the sulfonylation of 2-(trimethylsilyl)pyridine (1) with $\mathrm{SO}_{2}$ adduct DABSO. Addition of DABSO to a $\mathrm{CH}_{2} \mathrm{Cl}_{2}$ solution of $\mathbf{1}$ and methyliodide, in the presence of tetrabutylammonium triphenyldifluorosilicate (TBAT) as a fluoride source, resulted in the formation of the expected methylsulfone $1 \mathrm{a}$ in $>90 \%$ yield within $17 \mathrm{~h}$ at $25^{\circ} \mathrm{C}$ (Eq. 1). DABCO, $\mathrm{Ph}_{3} \mathrm{SiF}$, tetrabutylammonium iodide and $\mathrm{Me}_{3} \mathrm{SiF}$ were formed as byproducts.

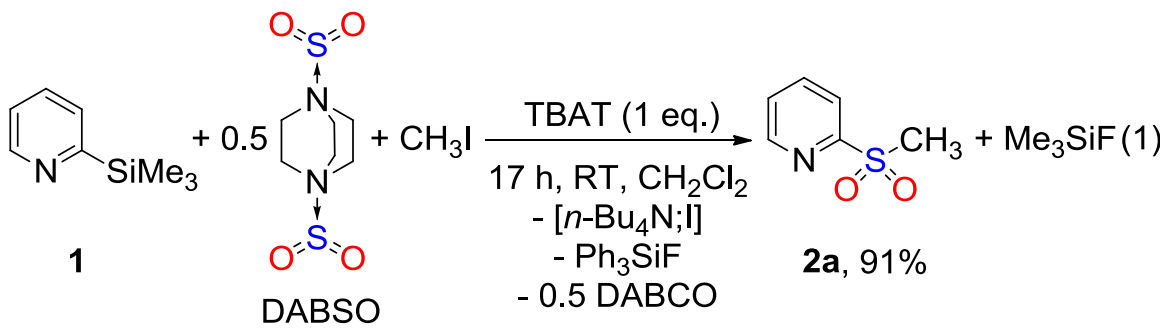

TBAT $=\left[\mathrm{n}-\mathrm{Bu}_{4} \mathrm{~N} ; \mathrm{Ph}_{3} \mathrm{SiF}_{2}\right]$

To the best of our knowledge, the conversion of $\mathbf{1}$ to $\mathbf{2 a}$ represents the first example of the direct sulfonylation of an organosilane reagent under metal-free conditions. 
Importantly, 1 selectively reacts with $\mathrm{SO}_{2}$ and no trace of pyridine or 2-methylpyridine was detected, that would result from quenching of the pyridine anion with protons or MeI, It is notable that, in the absence of $\mathrm{SO}_{2}$, no conversion of $\mathbf{1}$ was observed after $17 \mathrm{~h}$ at $25^{\circ} \mathrm{C}$, thereby suggesting that $\mathrm{SO}_{2}$ facilitates the $\mathrm{C}-\mathrm{Si}$ bond scission.[11]

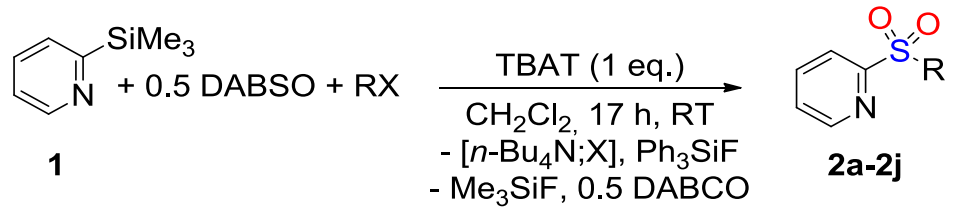

Table 1. Synthesis of sulfones by fluoride mediated sulfonylation of 2(trimethylsilyl)pyridine (1) with various electrophiles (Eq. 2).

\begin{tabular}{lll}
\hline Entry RX $\quad$ Product & Isolated yield [\%]
\end{tabular}

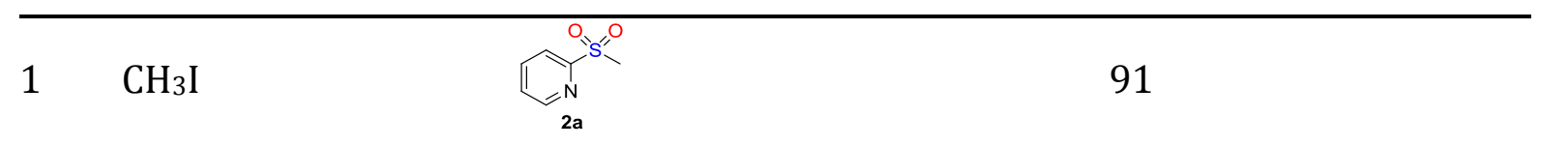

$2 \quad \mathrm{C}_{2} \mathrm{H}_{5} \mathrm{I}$

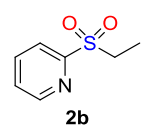

88

$\mathrm{C}_{6} \mathrm{H}_{13} \mathrm{I}$

$3 \quad \mathrm{C}_{6} \mathrm{H}_{13} \mathrm{Br}$

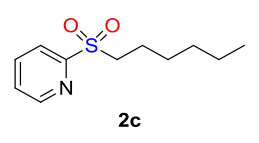

83

$\mathrm{C}_{6} \mathrm{H}_{13} \mathrm{Cl}$

$\mathrm{C}_{3} \mathrm{H}_{5} \mathrm{I}$

4

$\mathrm{C}_{3} \mathrm{H}_{5} \mathrm{Br}$

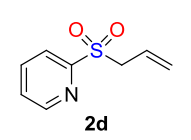

95

$5 \quad \mathrm{C}_{7} \mathrm{H}_{7} \mathrm{Br}$

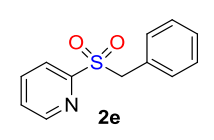

$6 \quad \mathrm{C}_{3} \mathrm{H}_{7} \mathrm{I}$

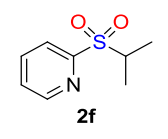

$7 \quad \mathrm{I}\left(\mathrm{CH}_{2}\right)_{4} \mathrm{I}$

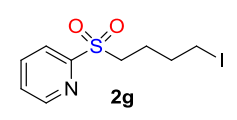

$8 \mathrm{BrCH}_{2} \mathrm{COOC}_{2} \mathrm{H}_{5}$

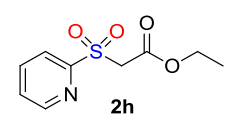

$9 \mathrm{CH}_{3} \mathrm{OC}_{6} \mathrm{H}_{4} \mathrm{COCH}_{2} \mathrm{Br}$

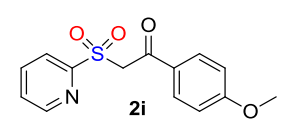


Reaction conditions: $\mathrm{Ar}-\mathrm{Si}(\mathrm{Me}){ }_{3}(0.5 \mathrm{mmol}), \mathrm{TBAT}$ (0.5 mmol), RX (0.5 mmol), DABSO (0.25 mmol), $\mathrm{CH}_{2} \mathrm{Cl}_{2}(1 \mathrm{~mL})$. a) NMR yield.

As pointed out by Willis et al., DABSO is a practical surrogate for $\mathrm{SO}_{2}$, as it is bench-stable and avoids the manipulation of a toxic and corrosive gas. ${ }^{[12]}$ Nonetheless, 2 a could also be successfully obtained in $71 \%$ yield by replacing DABSO with $\mathrm{SO}_{2}$ gas, highlighting that DABCO does not play an essential role in this transformation. Replacing MeI with other organo-halides, a large variety of 2-pyridylsulfone derivatives were successfully prepared (Eq. 2, Table 1). For example, sulfones 2a-2e were formed in excellent $71-96 \%$ yields using primary alkyl halides such as iodomethane, iodoethane, 1-iodohexane, 1bromohexane, allyl-iodide and -bromide and benzylbromide respectively (Table 1, entries 1-5). Although TBAT can be easily recycled by addition of TBAF to fluorotriphenylsilane,[13] the atom efficiency of the present transformation can be improved by utilizing $\mathrm{CsF}$ as a fluoride source, in a polar solvent such as $\mathrm{CH}_{3} \mathrm{CN}$. Under these conditions $\mathbf{2 e}$ is isolated in $77 \%$ yield (see SI). This reaction is tolerant towards several functional groups such as iodides $(\mathbf{2} \mathbf{g})$, esters $(\mathbf{2} \mathbf{h})$, ketones $(\mathbf{2} \mathbf{i})$ and nitriles $(\mathbf{2} \mathbf{j})$ (Table 1, entries 7-10). Introducing, an electron donating (3- $\mathrm{CH}_{3}, 5-\mathrm{CH}_{3}$ or 6- $\mathrm{CH}_{3}$ ) (EDGs) or withdrawing $\left(4-\mathrm{CF}_{3}\right)$ (EWGs) group on the pyridine ring of $\mathbf{1}$ did not influence significantly the reactivity of the organosilane reagent and sulfones $\mathbf{4 a - 4 d}$ were formed in $64-90 \%$ yield, with $\mathbf{4 b}\left(5-\mathrm{CH}_{3}\right)$ being the most reactive (Scheme 2$)$.

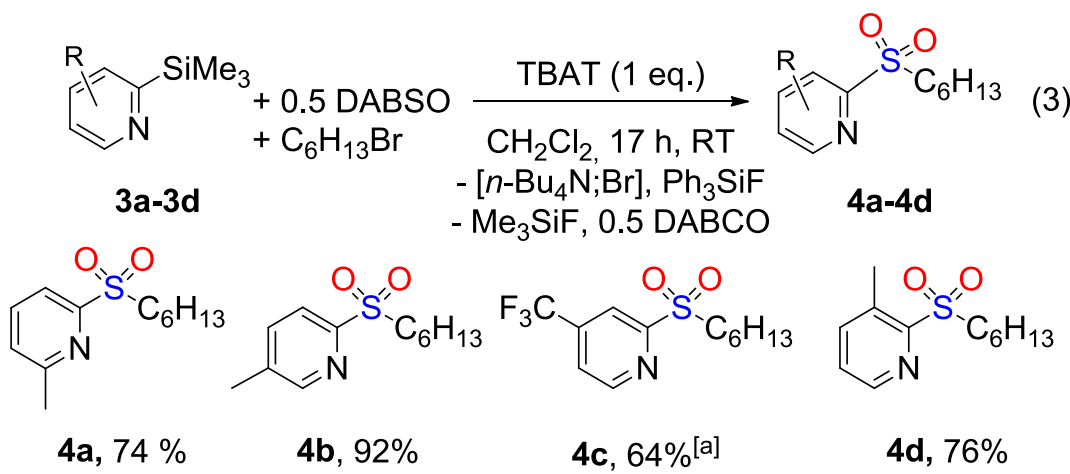

Scheme 2. Synthesis of (hexylsulfonyl)pyridine. Reaction conditions: $\operatorname{Ar}-\mathrm{Si}(\mathrm{Me})_{3}$ (0.5 mmol), TBAT (0.5 mmol), $\mathrm{C}_{6} \mathrm{H}_{13} \mathrm{Br}$ (0.5 mmol), DABSO (0.25 mmol), $\mathrm{CH}_{2} \mathrm{Cl}_{2}(1 \mathrm{~mL})$. [a] NMR yield determined with mesitylene as internal standard.

Disappointingly, trimethylphenylsilane (5) exhibits no reactivity in the presence of DABSO, EtI and CsF, thereby showing that the pyridine ring has a positive influence on the reaction of 1 with $\mathrm{SO}_{2}$. In order to promote the metal-free conversion of arylsilanes to aromatic sulfones, we sought to increase the Lewis acidity of silicon to facilitate the activation of the arylsilane by CsF. The sulfonation of triethoxyphenylsilane (6a) with 
DABSO, EtI and CsF indeed enables the formation of phenylethylsulfone $7 \mathbf{a}$ after $3 \mathrm{~h}$ at $80{ }^{\circ} \mathrm{C}$ in a low $5 \%$ yield. This poor conversion could be attributed to the competitive formation of the anion $\mathrm{FSO}_{2}{ }^{-}{ }^{-[14]}$ To shift this equilibrium towards the release of the active fluoride and $\mathrm{SO}_{2}$ sources, the conversion of a variety of aryltriethoxylsilanes possessing EDGs and EWGs groups (6a-6e) was attempted, with 6 equiv. CsF, 3 equiv. DABSO and 4 equiv. EtI, at $120^{\circ} \mathrm{C}$ (Scheme 3). The corresponding arylethylsulfones 7a-7e were successfully isolated in $33-97 \%$ with the electron deficient $\mathrm{C}_{6} \mathrm{~F}_{5} \mathrm{Si}(\mathrm{OEt})_{3}(\mathbf{6 e})$ derivative being the most reactive.

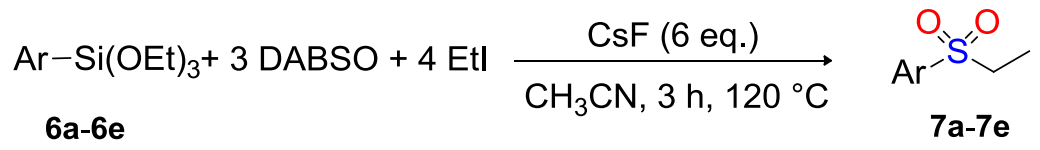
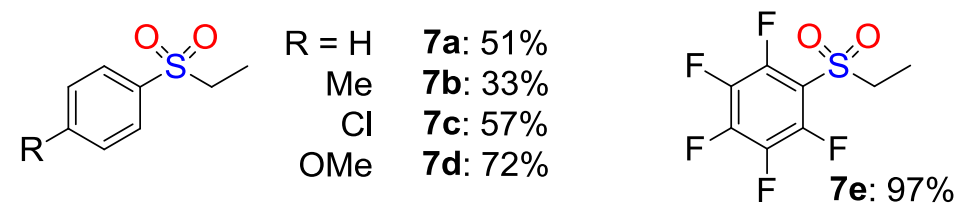

Scheme 3. Synthesis of arylsulfone. Reaction conditions: silane $(0.1 \mathrm{mmol}), \mathrm{CsF}$ (0.6 mmol), EtI (0.4 mmol), DABSO (0.3 mmol), $\mathrm{CH}_{3} \mathrm{CN}(1 \mathrm{~mL})$.

The formation of $\mathbf{2 a - 2} \mathbf{j}, \mathbf{4 a - 4 d}$ and $\mathbf{7 a - 7 e}$ represents the first examples of a metal-free synthesis of sulfones from (hetero)arylsilanes. From a mechanistic viewpoint, experiments showed that, in the presence of a fluoride source, the $\mathrm{C}-\mathrm{Si}$ bond scission of arylsilanes does not take place in the absence of $\mathrm{SO}_{2}$. Second, a marked difference in reactivity was observed between pyridyl- and phenyl-silane derivatives, the latter being less reactive. To address these questions, DFT calculations were performed for the sulfonylation of 2-(trimethylsilyl)pyridine (1) and trimethylphenylsilane (5) with $\mathrm{SO}_{2}$, $\mathrm{Me}_{3} \mathrm{SiF}_{2}{ }^{-}$and $\mathrm{MeI}$ (Scheme 4 and SI). 
a.

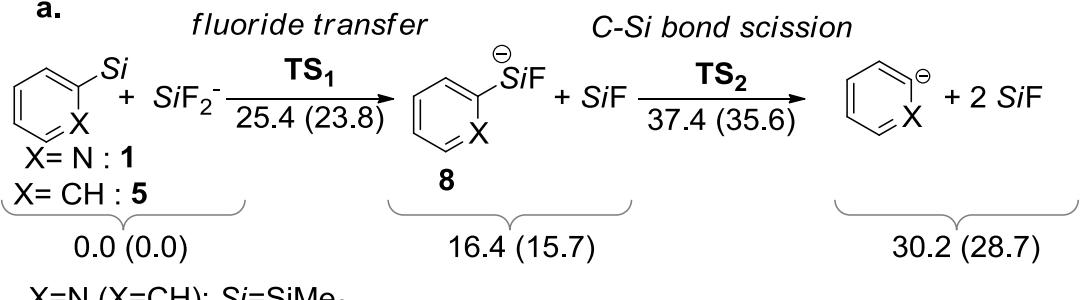

$\mathrm{X}=\mathrm{N}(\mathrm{X}=\mathrm{CH}) ; \mathrm{Si}=\mathrm{SiMe}_{3}$

b.
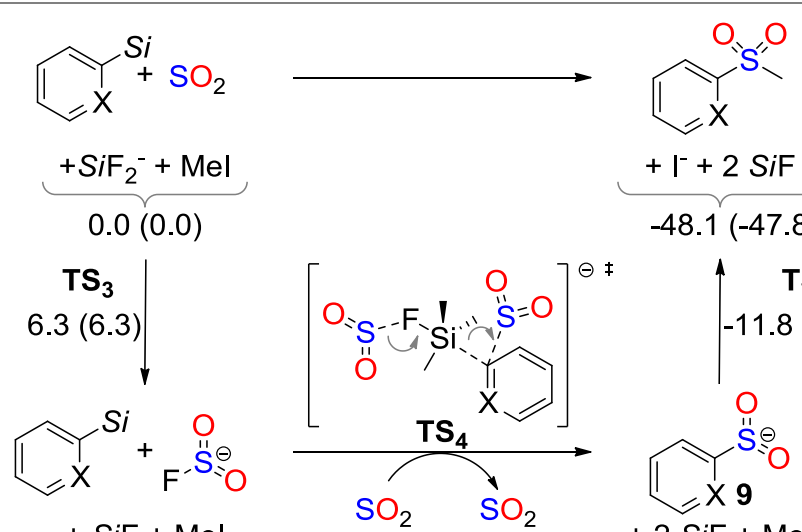

$$
\underbrace{+\mathrm{I}^{-}+2 \mathrm{SiF}}_{-48.1(-47.8)}
$$

$$
\underbrace{+\mathrm{SiF}+\mathrm{Mel}}_{-12.7(-12.7)}
$$

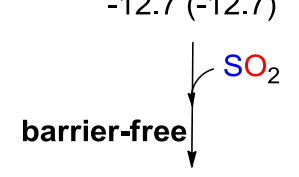<smiles></smiles>

10

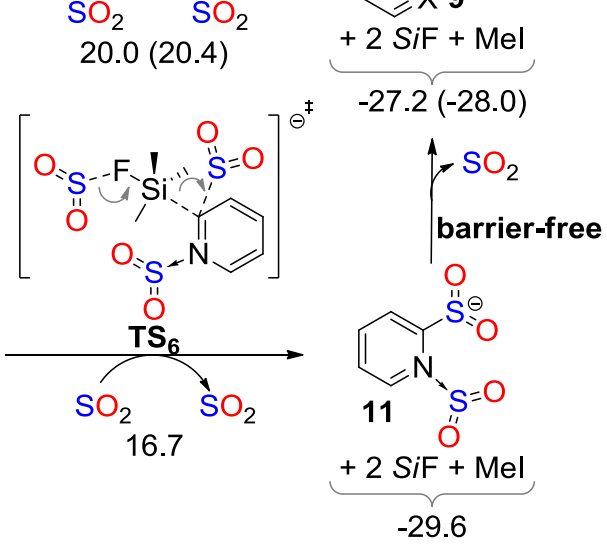

$\mathrm{X}=\mathrm{N}(\mathrm{X}=\mathrm{CH}) ; \mathrm{Si}=\mathrm{SiMe}_{3}$

c.
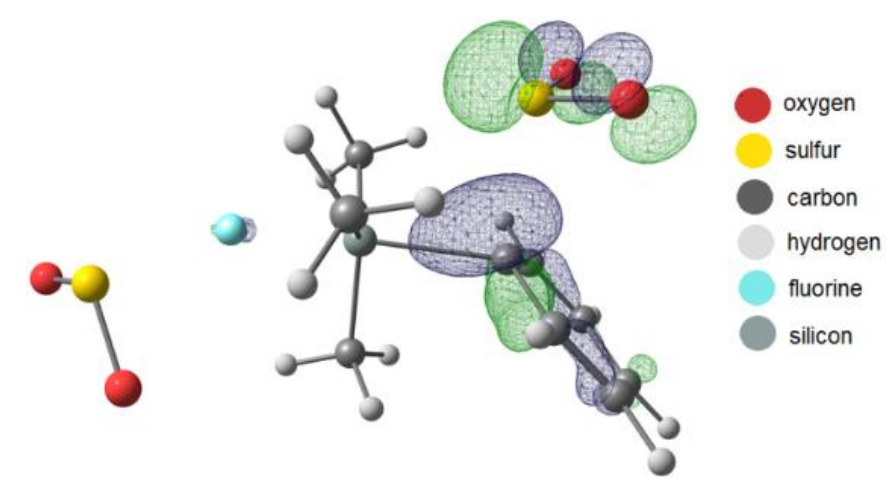

Scheme 4. Computed reaction pathways as calculated by DFT. Level of theory: PBE0/GD3 / 6-311+G(d) for all atom types / PCM=THF. Values given correspond to Gibbs free energies with respect to the starting material $\left(\Delta \mathrm{G}=0.0 \mathrm{kcal} . \mathrm{mol}^{-1}\right)$. a) fluoride-mediated activation of silanes $\mathbf{1}$ and $\mathbf{5}$ in the absence of $\mathrm{SO}_{2}$. Values given in parenthesis correspond to the conversion of $\mathrm{PhSiMe}_{3}$ (5). b) Proposed mechanism for the metal-free sulfonylation of silanes 1 and 5. c) Representation of the HOMO in $\mathbf{T S}_{\mathbf{4}}$ with X $=\mathrm{CH}$ (5) showing a strong electron delocalization over the $\mathrm{SO}_{2}$-fragment. 
The simplest pathway would rely on a fluoride transfer from the fluoride source to the organosilane and subsequent $\mathrm{C}-\mathrm{Si}$ bond cleavage of the hypervalent intermediate (8) to release the free pyridyl or phenyl anion (Scheme 4a). Nevertheless, this sequence can be discarded as it involves the unstabilized carbanions $\left(\Delta \mathrm{G}>28.7 \mathrm{kcal}^{\left.-\mathrm{mol}^{-1}\right)}\right.$ and transition states lying at least $35.6 \mathrm{kcal} \mathrm{mol}^{-1}$ higher than the starting materials. $\mathrm{As}^{\mathrm{SO}_{2}}$ has a positive influence on the early stages of the reaction, its role in the formation of $\mathbf{8}$ and the activation of the organosilane was investigated computationally (Scheme $4 \mathrm{~b}$ ). $\mathrm{SO}_{2}$ is a potent electrophile and it readily abstracts a fluoride anion from $\mathrm{Me}_{3} \mathrm{SiF}_{2}{ }^{-}$to yield the

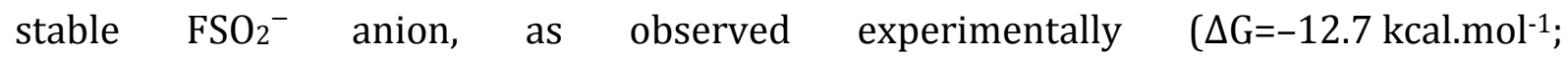
$\left.\Delta \mathrm{G}^{\ddagger}\left(\mathbf{T S}_{\mathbf{3}}\right)=6.3 \mathrm{kcal} \cdot \mathrm{mol}^{-1}\right)$. The stable $\mathrm{FSO}_{2}{ }^{-}$can then act as a fluoride transfer agent and a transition state ( $\mathbf{T S}_{\mathbf{4}}$ ) was located that connects phenylsilane $\mathbf{5}$ to the sulfinate anion $\mathbf{9}$, in the presence of a second molecule of $\mathrm{SO}_{2}$. $\mathbf{T S}_{4}$ only lies $20.4 \mathrm{kcal} \mathrm{mol}^{-1}$ above the starting materials and its low energy is attributed to the strong electrophilic character of $\mathrm{SO}_{2}$, able to stabilize the charge build-up on the aryl ring upon cleavage of the $\mathrm{C}-\mathrm{Si}$ bond. Indeed, the highest occupied molecular orbital (HOMO) of $\mathbf{T S}_{\mathbf{4}}$ shows a large delocalization of the carbon lone pair onto the $\mathrm{SO}_{2}$ fragment, with a minimum structural perturbation of $\mathrm{SO}_{2}$ $\left(\mathrm{OSO}=114.4^{\circ}\right.$ vs. $117.6^{\circ}$ in free $\mathrm{SO}_{2}$, mean S-O bond lengths of $1.47 \AA$ vs. $1.45 \AA$ in free $\mathrm{SO}_{2}$ ) (Scheme 4c). The so-formed arylsulfinate anion $9\left(-28.0 \mathrm{kcal}^{\mathrm{mol}}{ }^{-1}\right)$ could then undergo S-alkylation via transition state $\mathbf{T S}_{\mathbf{5}}\left(-11.5 \mathrm{kcal}_{\mathrm{mol}}{ }^{-1}\right)$ to afford the final sulfone product $\left(-47.8 \mathrm{kcal}_{\mathrm{mol}}^{-1}\right)$. This pathway helps rationalize the positive effect of $\mathrm{SO}_{2}$ in the activation of the organosilane reagent. Nonetheless, it fails to account for the difference in reactivity between $\mathbf{1}$ and $\mathbf{5}$, as similar energy barriers are computed for the two substrates (20.0 vs $20.4 \mathrm{kcal}^{\mathrm{mol}}{ }^{-1}$ ).

Reasoning that the nitrogen atom of the pyridyl ring could also interact with $\mathrm{SO}_{2}$, the formation of adduct $\mathbf{1 0}$ was computed. Interestingly, sulfonylation of $\mathbf{1}$ leading to $\mathbf{1 0}$ is barrier-less and only slightly endergonic $\left(\Delta \mathrm{G}=12.2 \mathrm{kcal}^{\mathrm{mol}} \mathrm{mo}^{-1}\right)$. The sulfonylation of the $\mathrm{C}-$ $\mathrm{Si}$ bond, in the presence of $\mathrm{FSO}_{2}^{-}$, then proceeds via $\mathbf{T S}_{6}$ to yield sulfinate $\mathbf{1 1}$. Decoordination of $\mathrm{SO}_{2}$ from 11 is again barrier-free and it releases the expected sulfinate anion 9. Importantly, TS 6 displays similar features to $\mathbf{T S}_{\mathbf{4}}$ and the extra stabilization provided by the $\mathrm{N}-\mathrm{SO}_{2}$ interaction translates into a $3.3 \mathrm{kcal} \mathrm{mol}^{-1}$ stabilization of $\mathbf{T S}_{\mathbf{6}}$ compared to $\mathbf{T S}_{\mathbf{4}}$. Overall, these mechanistic trends unveil a multiple catalytic influence of $\mathrm{SO}_{2}$ in the sulfonylation of $\mathbf{1}$ and $\mathbf{5}$. First, $\mathrm{SO}_{2}$ behaves as an efficient fluoride carrier via the reversible formation of $\mathrm{FSO}_{2}{ }^{-}$. Second, it facilitates the $\mathrm{C}-\mathrm{Si}$ bond cleavage of $\mathbf{1}$ by reversible coordination to the $\mathrm{N}$ atom of the pyridine ring. This kinetic behavior is attributed to the electronic and geometric structure of $\mathrm{SO}_{2}$. With a bent structure and a low lying $\pi^{*}$ vacant orbital perpendicular to the $(0, S, 0)$ plane and polarized towards the sulfur atom, $\mathrm{SO}_{2}$ is poised towards nucleophilic attack. In fact, we computed that the elongation of the S-O bonds does not exceed $9.8 \%$ and the bending of the $\mathrm{O}-\mathrm{S}-\mathrm{O}$ angle remains small (9.7\%) upon formation of $\mathrm{FSO}_{2}{ }^{-}, \mathbf{9}, \mathbf{1 0}$ and $\mathbf{1 1}$. These findings suggest that the sulfonylation of other mild nucleophiles could be facilitated by $\mathrm{SO}_{2}$, such as the sulfonylation of $\mathrm{C}-\mathrm{H}, \mathrm{N}-\mathrm{H}$ or $\mathrm{N}-\mathrm{Si}$ bonds, under metal-free conditions. 
In conclusion, we have shown that sulfones can be accessed under metal-free conditions for the first time from both heteroaryl and arylsilanes, in the presence of $\mathrm{SO}_{2}$ or a surrogate, the activation of the organosilane being promoted by a fluoride source. Mechanistic investigations show that $\mathrm{SO}_{2}$ is an excellent electrophile, able to synchronize a fluoride mediated $\mathrm{C}-\mathrm{Si}$ bond cleavage with $\mathrm{C}-\mathrm{S}$ bond formation.

\section{Experimental Section}

Detailed descriptions of experimental and computational methods are given in the Supporting Information.

\section{Acknowledgements}

For financial support of this work, we acknowledge CEA, CNRS, the CHARMMMAT Laboratory of Excellence and the European Research Council (ERC Starting Grant Agreement n.336467). We thank CINES (project c2016086494) for computational time. T.C. thanks the Foundation Louis D. - Institut de France for its support.

Keywords: $\mathrm{SO}_{2} \bullet \operatorname{organosilanes} \bullet$ sulfones $\bullet$ metal-free $\bullet$ DFT calculations

[1] a) K. Tanaka, A. Kaji, in Sulphones and Sulphoxides (1988), John Wiley \& Sons, Ltd, 2006, pp. 759-821; b) K. Schank, in Sulphones and Sulphoxides (1988), John Wiley \& Sons, Ltd, 2006, pp. 165-231; c) N. Furukawa, H. Fujihara, in Sulphones and Sulphoxides (1988), John Wiley \& Sons, Ltd, 2006, pp. 541-581; d) J. Shorter, in Sulphones and Sulphoxides (1988), John Wiley \& Sons, Ltd, 2006, pp. 483-540.

[2] a) P. F. Schellhammer, Expert Opin. Pharmacother. 2002, 3, 1313-1328; b) P. TfeltHansen, P. Vries, P. R. Saxena, Drugs 2012, 60, 1259-1287; c) P. Prasit, Z. Wang, C. Brideau, C. C. Chan, S. Charleson, W. Cromlish, D. Ethier, J. F. Evans, A. W. FordHutchinson, J. Y. Gauthier, R. Gordon, J. Guay, M. Gresser, S. Kargman, B. Kennedy, Y. Leblanc, S. Léger, J. Mancini, G. P. O'Neill, M. Ouellet, M. D. Percival, H. Perrier, D. Riendeau, I. Rodger, P. Tagari, M. Thérien, P. Vickers, E. Wong, L. J. Xu, R. N. Young, R. Zamboni, S. Boyce, N. Rupniak, M. Forrest, D. Visco, D. Patrick, Bioorg. Med. Chem. Lett. 1999, 9, 1773-1778.

[3] a) S. S. James D. Rodgers, Argyrios G. Arvanitis, Haisheng Wang, Louis Storace, Beverly Folmer, Lixin Shao, Wenyu Zhu, Joseph P. Glenn, in 2010, Vol. WO 2010135650, Incyte Corporation, USA, 2010; b) F. E. Himmelsbach, Matthias; Heine, Niklas; Langkopf, Elke; Nosse, Bernd, Vol. WO 2012080476, Boehringer Ingelheim International GmbH, Germany, 2012.

[4] a) A. Shaabani, P. Mirzaei, S. Naderi, D. G. Lee, Tetrahedron 2004, 60, 11415-11420;

b) R. J. Griffin, A. Henderson, N. J. Curtin, A. Echalier, J. A. Endicott, I. R. Hardcastle, D. R. Newell, M. E. M. Noble, L.-Z. Wang, B. T. Golding, J. Am. Chem. Soc. 2006, 128, 60126013; c) K. D. James, N. N. Ekwuribe, Synthesis 2002, 2002, 0850-0852; d) H. 
Meerwein, G. Dittmar, R. Göllner, K. Hafner, F. Mensch, O. Steinfort, Chem. Ber. 1957, 90, 841-852.

[5] a) E. J. Emmett, B. R. Hayter, M. C. Willis, Angew. Chem. 2013, 125, 12911-12915; b) E. J. Emmett, B. R. Hayter, M. C. Willis, Angew. Chem. Int. Ed. 2013, 52, 12679-12683; c) A. S. Deeming, C. J. Russell, M. C. Willis, Angew. Chem. Int. Ed. 2015, 54, 1168-1171; d) A. S. Deeming, C. J. Russell, M. C. Willis, Angew. Chem. 2015, 127, 1184-1187.

[6] a) B. N. Rocke, K. B. Bahnck, M. Herr, S. Lavergne, V. Mascitti, C. Perreault, J. Polivkova, A. Shavnya, Org. Lett. 2014, 16, 154-157; b) A. Shavnya, K. D. Hesp, V. Mascitti, A. C. Smith, Angew. Chem. Int. Ed. 2015, 54, 13571-13575; c) A. Shavnya, K. D. Hesp, V. Mascitti, A. C. Smith, Angew. Chem. 2015, 127, 13775-13779; d) A. Shavnya, S. B. Coffey, A. C. Smith, V. Mascitti, Org. Lett. 2013, 15, 6226-6229.

[7] a) M. W. Johnson, S. W. Bagley, N. P. Mankad, R. G. Bergman, V. Mascitti, F. D. Toste, Angew. Chem. Int. Ed. 2014, 53, 4404-4407; b) M. W. Johnson, S. W. Bagley, N. P. Mankad, R. G. Bergman, V. Mascitti, F. D. Toste, Angew. Chem. 2014, 126, 4493-4496.

[8] D. Zheng, R. Mao, Z. Li, J. Wu, Org. Chem. Front. 2016, 3, 359-363.

[9] a) M. Onoe, K. Baba, Y. Kim, Y. Kita, M. Tobisu, N. Chatani, J. Am. Chem. Soc. 2012, 134, 19477-19488; b) L. Li, Y. Zhang, L. Gao, Z. Song, Tetrahedron Lett. 2015, 56, $1466-$ 1473; c) S. E. Denmark, C. S. Regens, Acc. Chem. Res. 2008, 41, 1486-1499; d) Y. Hatanaka, T. Hiyama, J. Org. Chem. 1988, 53, 918-920; e) R. Walsh, Acc. Chem. Res. 1981, 14, 246-252.

[10] X. Frogneux, N. v. Wolff, P. Thuéry, G. Lefèvre, T. Cantat, Chem. Eur. J. 2016, 22, 2930-2934.

[11] Importantly, in the absence of $\mathrm{SO}_{2}, \mathrm{DABCO}$ alone is not able to activate the $\mathrm{C}-\mathrm{Si}$ bond and the starting materials are recovered under these conditions.

[12] B. Nguyen, E. J. Emmett, M. C. Willis, J. Am. Chem. Soc. 2010, 132, 16372-16373.

[13] C. Eaborn, J. Chem. Soc. 1952, 2846-2849.

[14] a) E. Lork, R. Mews, D. Viets, P. G. Watson, T. Borrmann, A. Vij, J. A. Boatz, K. O. Christe, Inorg. Chem. 2001, 40, 1303-1311; b) K. C. Lobring, C. E. Check, L. S. Sunderlin, Int. J. Mass spectrom. 2003, 222, 221-227; c) S. T. Arnold, T. M. Miller, A. A. Viggiano, J. Phy. Chem. A 2002, 106, 9900-9909. 